\title{
THOMAZ DE MELLO BREYNER: EXCERTOS E PRISMAS DE UM DIÁRIO
}

\author{
THOMAZ DE MELLO BREYNER: EXCERPTS \\ AND VIEWS OF A DIARY
}

Maria Alice Ribeiro Gabriel ${ }^{1}$

\section{RESUMO}

Thomaz de Mello Breyner nasceu em Lisboa em 1866, filho de Francisco de Mello Breyner, $2^{\circ}$ Conde de Mafra. Atuando como médico familiar na corte de Dom Carlos I de Portugal, Breyner concedeu um interessante relato em primeira-mão dos últimos anos da monarquia portuguesa, entrelaçado com recordações de sua atividade clínica e vida doméstica. Após redigir dois volumes narrando sua infância e adolescência, falece em Lisboa, em 1933, aos 67 anos, sem completar suas memórias. Entre seus descendentes inclui-se a poeta e escritora Sophia de Mello Breyner Andresen, mas ele é frequentemente lembrado por seu testemunho sobre as mudanças ocorridas em Portugal, particularmente na medicina e política, no final do século XIX e início do século XX. Entretanto, os atributos literários de seus escritos têm sido ofuscados por seu valor histórico. O objetivo deste artigo é comentar aspectos históricos e biográficos de suas memórias, baseando-se especialmente em Diário de um monárquico: 1908-1910 (1993).

PALAVRAS-CHAVE: Thomaz de Mello Breyner; diário; memórias.

\section{ABSTRACT}

Thomaz de Mello Breyner was born in Lisbon in 1866, the son of Francisco de Mello Breyner, 2nd Count of Mafra. Acting as family physician at the court of Dom Carlos I of Portugal, Breyner gave a interesting first-hand account of the last years of Portuguese monarchy, interwoven with records of his clinical labor and domestic life. After writing the first two books narrating his childhood and adolescence, he passed away in Lisbon in 1933, at the age of 67 years, without completing his memories. Breyner's descen- 
dants include the poet and writer Sophia de Mello Breyner Andresen, but he is often remembered for his testimony about the changes that occurred in Portugal, particularly in medicine and policy, at the end of the XIX Century and start of the XX Century. However, the literary atributtes of his writings was overshadowed by its historial value. The aim of this paper is to comment historical and biographical aspects in his memories, foccusing especially on Diário de um monárquico: 1908-1910 (1993).

KEYWORDS: Thomaz de Mello Breyner; diary; memories.

\section{CONSIDERAÇÕES INICIAIS}

O Livro I das Confissões (397-400) é dedicado à infância, seguido dos relatos da adolescência, juventude e maturidade de Santo Agostinho. As memórias de Infância (1852), Adolescência (1854), Juventude (1856) e Crônicas de Sebastopol (1855-1856) são os primeiros escritos de Leon Tolstoi, marco inicial de seu extenso percurso literário. Além de seu diário, que ele avaliou como sendo seu legado escrito mais importante (LEO, 2014), o autor deixou ainda 31 cadernos de notas autobiográficas com referências às suas obras. Thomaz de Mello Breyner, como Pedro Nava, já havia praticamente concluído uma bem-sucedida carreira médica quando passou a organizar e redigir seus escritos autobiográficos, vertendo-os para a forma de memórias literárias.

Se a última linha do diário de Tolstoi foi escrita 4 dias antes de sua morte, esta lacuna ou silêncio pertence igualmente à sua história, do mesmo modo que rasuras ou mutilações póstumas a qualquer acervo biográfico. $\mathrm{O}$ arquivo pessoal de um escritor também integra suas memórias - caso de Pedro Nava, cujos cadernos expõem desenhos do autor, recortes de jornais e outros souvenirs complementando anotações pessoais.

Justo por sua inerente complexidade, quando submetidos ao tradicional critério literário da academia, os escritos memorialísticos pairam entre dois extremos: aquele ocupado por textos artisticamente elaborados, conforme Antonio Candido (1989, p. 53): “[...] alguns livros autobiográficos de cunho francamente poético e ficcional, aliás muito diferentes entre si”, a exemplo das obras de Santo Agostinho, Dostoiévski, Miguel Torga e Pedro Nava, que harmonizam diferentes discursos; e o espaço destinado a relatos julgados essenciais pelo valor de fonte documental histórica ou de apoio à pesquisa de outros acervos, como Diary, Reminiscences and Correspondence (1869), de Henry Crabb Robinson, tão representativo para se entender a perspectiva do autor em seu próprio tempo quanto para o pesquisador de William Blake (MISHRA, 1990, p. 27).

Castelo Branco Chaves (1978, p. 6) subdividiu a moderna memorialística portuguesa em dois ramos autobiográficos: memórias e diários, modalidades distintas do gênero quanto ao modo de relatar fatos e assuntos significativos para o memorialista: 
Com as memórias de Raúl Brandão, com as de Aquilino, com as de Sarmento Pimentel e com as de José Relvas, a literatura memorialística portuguesa ficou enriquecida com obras de mérito literário que até aí não possuíra. São ainda de considerar pelo seu mérito memorialístico as Memórias do Sexto Marquês de Lavradio e as memórias de Tomás de Mello Breyner, que o autor deixou incompletas. (CHAVES, 1978, p. 17)

A versatilidade do gênero memorialístico foi assinalada por Jerome de Groot (2016, p. 41), que destacou duas características comuns à autobiografia e ao diário: primeiramente, ambos encerram a promessa de informações e revelações excluídas por biografias oficiais e por relatos da Historiografia; segundo, o leitor geralmente se interessa por detalhes da vida privada e pela descoberta de possíveis motivações íntimas subentendidas em fatos marcantes - o diário e a biografia combinariam tais aspectos. A ponderação de Groot encontra ressonância no seguinte comentário de Antonio Candido:

Para ser exato, é preciso dizer que Minas produziu também autobiografias medíocres no século XIX, como as Minhas memórias, do Visconde de Nogueira da Gama, descosidas apesar de contar fatos curiosos e transcrever documentos importantes. Em compensação, nos últimos anos do século Helena Morley enchia os seus cadernos com essa flor de graça e verdade que é Minha vida de menina, uma das obras-primas da literatura pessoal no Brasil. (CANDIDO, 1989, p. 53)

Se a memorialística oscila entre os polos da Historiografia e da Literatura, obras como Minha vida de menina (1942), de Alice Dayrell Caldeira Brant, dividem os críticos, não pelo valor literário, mas pela autenticidade diacrônica de sua elaboração; já o recurso ao estilo diarístico como representação ficcional na literatura portuguesa moderna foi avaliado por Hans Paschen (2002) nas narrativas de Mário de Sá-Carneiro.

Para Trevor Field, a questão não é se o diário em forma de novela é um falso diário. Conjugados, diário e novela produziriam uma tensão criativa: não se trata de sanar o contraste por meio da transferência das qualidades do gênero mais subserviente, absorvido pelo predominante e, no caso da novela diarística, as demandas da literatura impediriam uma imitação total, por exemplo, uma versão ficcional de Mes Cahiers (18961918), de Maurice Barrès, teria o aspecto de mera imitação de notas soltas, que certamente não poderiam constituir uma novela. Citando o crítico Jacques Chocheyras (1978 apud FIELD, 1989, p. 20), o autor considerou o diário pessoal ou jornal íntimo a única forma literária por definição inacabada, desde que certas novelas diarísticas (como determinados tipos de ficção moderna) terminam inconclusivamente, mais por uma reflexão de escolha artística deliberada que por quaisquer arbitrariedades cotidianas.

Comentando Ao Farol (1927), Daniel R. Schwarz (2003, p. 214) observou que a novela permitiu a Virginia Woolf sondar a conexão entre 
arte e vida, memória e experiência, além de expor o papel da criação artística nas operações de ordenação e distorção que a memória projeta sobre os fatos. Conforme o autor, a obra evidenciaria o envolvimento da memória e criatividade artística na habilidade mental de ressignificar o passado e de informar o presente com os insights produzidos por esses significados. Ao elaborar a obra memorialística, as "distorções" da memória seriam a ponte que separa ficção e realidade (entendida como verdade histórica). Segundo Castelo Branco Chaves:

\begin{abstract}
Menos interessantes que as memórias, são os diários. Dignos de maior confiança quanto ao rigor do que narram e à veracidade do que testemunham, porque elaborados ao sabor dos trabalhos e dos dias, não pecam por perspectivas estilizadas, como é vulgar suceder com as memórias. Estas, escritas geralmente no fim da vida do autor, iludem bastas vezes pelas miragens do passado que são, em muitos casos, tão enganosas como as do futuro. (CHAVES, 1978, p. 8)
\end{abstract}

Desiré Wakabwe (2005, p. 122) apontou as memórias como gênero contíguo à novela, limitado por ambiguidades presentes na relação entre autor-narrador-leitor, e pela natureza do contrato implícito nesta relação; já o diário permitiria acesso mais imediato à emoção e ao questionamento, por fundamentar-se na experiência pessoal. No entanto, segundo Field (1989, p. 20), se a novela diarística deve ser julgada objeto da literatura, é preciso reconsiderar a distinção entre literário e não literário antes de avaliar o diário privado como forma literária. Seguindo esta premissa, sem se deter na análise histórica e comparativa, o propósito central deste artigo é expor uma visão de conjunto de Diário de um monárquico: 1908-1910, comentando aspectos históricos e biográficos.

\title{
APONTAMENTOS BIOGRÁFICOS
}

Filho mais novo de Francisco de Mello Breyner e de Emília Pecquet da Silva, segundos Condes de Mafra, Thomaz de Mello Breyner, $4^{\circ}$ Conde de Mafra por autorização de D. Manuel II no exílio, nasceu em Lisboa a 2 de setembro de 1866 e faleceu nessa mesma cidade a 24 de outubro de 1933. A história dos Condes de Mafra vincula-se ao "Palácio da Costa" ou "Vila Flor", uma das primeiras edificações entre as "casas da Costa do Castelo", erigidas ao redor da antiga fortaleza lisboeta de São Jorge:

Foi neste prédio que, em 2 de Setembro de 1866, nasceu uma das figuras mais curiosas da aristocracia portuguesa dos últimos tempos, médico e professor erudito, o fidalgo $\mathrm{D}$. Tomás de Melo Breyner. Seu pai, o general D. Francisco de Melo Breyner, alugara, tempos antes, por ter sido nomeado comandante do regimento de Caçadores 5, aquartelado no Castelo de São Jorge, o andar nobre do palácio dos Sequeiras Pinto. (ANDRADE, 1960, p. 30)

Conforme relatou Margarida de Magalhães Ramalho (2016), Breyner "foi um filho tardio", nascido após a morte de duas irmãs mais no- 
vas vitimadas pela difteria, o que levou os pais a cercarem-no de cuidados. Porém aos três anos adoece, devido a uma febre cerebral: "O pai, desesperado, nunca abandonou sua cabeceira”. Nesse episódio é decisiva a atuação de Carlos Miguel Augusto May Figueira (1829-1913), catedrático da Escola Médica-Cirúrgica de Lisboa, precursor dos estudos de microscopia (BERNARDO, 2009, p. 672) e da fotografia médica em Portugal (CLOUDE, 2010, p. 15). É possível que tenha sido um dos modelos para a escolha profissional de Breyner:

Meu Pae tinha pelo professor May Figueira - lente, como se dizia nesse tempo - uma verdadeira adoração e gratidão por ter sido ele quem me salvou em pequeno de uma febre cerebral (...) Vi-o fazer photographias quando ainda se preparavam as chapas na ocasião o que ele executava com a maior habilidade, não deixando cair no chão uma só gota de colódio. O ensino foi a sua paixão. (BREYNER, 1930, p. 262 apud CLODE, 2010, p. 16).

Breyner frequentou o Colégio Acadêmico Lisbonense e a Escola Politécnica, formando-se na Escola Médica-Cirúrgica de Lisboa. Em 1893, após especializar-se em França, concorreu a um cargo no Hospital de São José, onde trabalhava seu mestre José Thomaz Sousa Martins, médico, cientista e professor da Escola Médica-Cirúrgica de Lisboa. Logo é nomeado médico da Real Câmara por D. Carlos I. "Foi depois, até â República, médico da Casa Real" (LOPES, 2013, p. 271). No ano seguinte desposa Sophia de Carvalho Burnay, filha dos primeiros Condes de Burnay (BREYNER, 2008).

Segue para Viena em 1897, acompanhando o Dr. Sousa Martins ao congresso sobre peste bubônica. Reportando-se aos apontamentos de Breyner, Francisco Antônio Gonçalves Ferreira comenta significativo fato ocorrido nesse período: "Uma consulta externa de doenças venéreas foi fundada no Hospital do Desterro em 1897 [...] que serviu de verdadeiro modelo para a fundação de dispensários antivenéreos por todo o País no século XX" (FERREIRA, 1990, p. 260). Mais tarde, na presidência do conselho de ministros, João Franco encarrega-o "[...] da 'reorganização do serviço de meretrizes' (sic) (19 de junho de 1906). E de facto caber-lhe-á a criação do serviço de dermatologia e doenças venéreas do Hospital do Desterro" (GRAÇA, 2005). Uma anotação feita em novembro de 1910 sugere ainda resquícios da "bubônica" que varrera a Europa entre 1894 e 1891:

Tempo lindo. Houve hoje um caso de bubônica na minha enfermaria - Santa Maria Madalena - no Desterro (...) É uma meretriz chamada Deolinda que veio do Bêco das Cruzes, exactamente o foco dos casos que houve há dias. (BREYNER; ANDRESEN, 1993, p. 324)

Anotações como essa denotam a rotina hospitalar e as preocupações de Breyner na administração dos problemas sanitários na área sob sua jurisdição, após ser nomeado, a partir de 1907, diretor de serviço clínico dos Hospitais Civis de Lisboa. 
Ainda, em 1903 e 1905, representara Portugal no Congresso Internacional de Medicina, respectivamente, em Madrid e Paris. Em 1906, participa do Congresso em Lisboa, como secretário da comissão executiva. Além dos problemas médico-sanitários locais, a inquietação com o destino da dinastia de Bragança é notada muitas vezes no diário do médico e amigo da Casa Real. Em 8 de Dezembro de 1907, pouco antes do regicídio de 1 de Fevereiro de 1908, escreve: "Onde está o meu Rei estou eu, sobretudo agora em tempo quase de guerra" (BREYNER, 2003, p. 344 apud GRAÇA, 2005). A princípios de janeiro de 1908, mostra-se abatido e pessimista sobre o momento político:

Eu fui jantar a casa do Marquês da Foz, no Campo de Sant'Anna. Dia lindo e eu muito cançado e triste. Não sei o que me adivinha o coração. Acho má a política. O João Franco parece doido. Quem paga as differenças é El-Rei. Achei hontem este Senhor triste, perguntando-me pelo estado dos espíritos, o que elle d'antes nunca fazia. (BREYNER; ANDRESEN, 1993, p. 18)

"Acaba-se hoje um ano que não me deixa as menores saudades. Praza a Deus que o próximo seja melhor. Saúde para os meus, para o Rei e para a Pátria é que se deseja e também para o João Franco", anotara em 31 de Dezembro de 1907. "Estava longe de imaginar que, dentro de um mês, estaria a chorar a perda dos seus queridos Rei e Príncipe Real e a embalsamar os seus corpos" (GRAÇA, 2005). Meses depois, em 30 de setembro de 1908, percorre, melancólico, as dependências do palácio: "Paço Real de Mafra. De manhã trabalhei no meu escritório. Depois fui com meu filho José Thomaz aos quartos de El-Rei onde não ia desde que O mataram. Que saudades. Rezamos os dois um padre nosso pela sua alma" (BREYNER; ANDRESEN, 1993, p. 99). Amigo desde a infância de Dom Carlos, pela convivência próxima de suas famílias, Breyner partilharia do sofrimento dos sobreviventes com outro olhar, além daquele do médico e súdito leal.

Anos depois, por ocasião da Primeira Grande Guerra: “Apesar de monárquico foi, pelas suas qualidades humanas e de clinico, convidado a encabeçar a formação sanitária da Cruz Vermelha que deveria partir para França em Março de 1917" (RAMALHO, 2014). Mas, por razões desconhecidas, na véspera da partida o ministro de França em Lisboa recusa-se a visar-lhe o passaporte diplomático. A decisão é revogada no dia seguinte, com um pedido de desculpas. Padecendo de diabetes, sentindo-se velho e sem ânimo, segundo Ramalho, o médico mantém a decisão de permanecer em Lisboa:

No seu diário escreverá: "A verdade é que a missão a França tem de arranjar outro chefe. Desde que ao meu sacrifício tremendo se corresponde com uma dúvida sobre a minha pessoa não há força que me faça partir." (...) Aconselhará, então que o substituam por Jorge Cid que " $\bar{E}$ inteligente é teso, falla bem francês e é amigo do João Chagas ministro ali.”. Dias depois, aliviado escrevia no seu diário «que bom anjo 
da guarda eu tenho "que rica ideia", bem haja o ministro da França que poz difficuldades no meu passaporte. Que juízo eu tive em não aceitar emendas!” (BREYNER apud RAMALHO, 2014).

Breyner faleceu em Lisboa a 24 de Outubro de 1933, deixando somente dois volumes de memórias sobre a infância e a adolescência: "Esse tempo que a memória se compraz em evocar é representado como uma idade de oiro, como uma era de felicidade, alegre despreocupação e abundância” (ROCHA, 1992, p. 185). A primeira parte de suas memórias descreve o período dos quatro aos catorze anos de idade:

O segundo volume refere-se aos anos de 1880 a 1883, entre os seus catorze e dezassete anos, interrompido pouco antes de adoecer e já muito perto da sua morte, com grande tristeza por o não poder terminar e escrever os que se iriam seguir. Antes de morrer ainda disse “.... porém os elementos cá ficam todos. Vocês farão o resto". (BREYNER; ANDRESEN, 1993, p. 6).

Segundo observaria Castelo Branco Chaves, embora o projeto autobiográfico de Breyner tenha sido interrompido com apenas duas obras concluídas, essas memórias:

Estão, porém, recheadas de reminiscências da infância que o autor conta com grande pitoresco e lhanesa, desenhando com sabor expressivo muitas figuras que conheceu desde a sua infância, galeria que vai dos criados da sua casa, aos quais se mostra em extremo dedicado, até reis e rainhas que serviu e com quem conviveu. (CHAVES, 1978, p. 51)

A trilogia formada por Diário de um monárquico: 1902-1904 (2005); Diário de um monárquico: 1908-1910 (1993) e Diário de um monárquico: 1911-1913 (1994) relata os últimos tempos da Monarquia até a República: "O diário, manuscrito, foi transcrito e anotado pelo seu neto Gustavo de Mello Breyner Andresen, e publicado pela Fundação Eng. António de Almeida" (GRAÇA, 2005). Em "Nota prévia" às memórias do avô materno, Andresen comenta seu traço sóbrio e conciso: "O diário está escrito sem preocupações literárias, em estilo de relato como, naturalmente, acontece a quem escreve notas ou apontamentos do dia a dia, embora soubesse escrever e bem" (BREYNER; ANDRESEN, 1993, p. 6). Os diários de Thomaz de Mello Breyner foram depositados por Ana Isasca Dias Marques Andresen e Xavier Dias Marques Andresen no Arquivo Nacional da Torre do Tombo em 16 de julho de 2015.

Do acervo memorialístico legado por Breyner constam oito cadernos de notas, redigidas de 1880 a 1895; quarenta agendas, abrangendo o período de 1897 a 1933 e um registro de consultas. Os diários possuem relação de complementaridade com os seguintes documentos e fundos arquivísticos do ANTT: Casa Real; Diário de D. Manuel II; Henry Burnay; Casa da Várzea de Abrunhais e Henrique de Paiva Couceiro. 
Segundo José Tomaz Mello Breyner, bisneto do autor, "[...] o $4^{\circ}$ Conde de Mafra - desde muito novo começou a escrever o seu diário. Deixou-nos 34 anos de diários escritos" (2008). A maior parte das passagens selecionadas neste estudo concerne aos primeiros anos do século XX. Apesar do hiato que separa as obras autobiográficas da juventude e o diário do homem maduro, o acervo memorialístico de Breyner ofereceria à História cultural e à Literatura promissora fonte de pesquisa, pelo testemunho in loco e relação direta com cenas da vida social e política do extinto Portugal da Belle Époque.

\section{O DIÁRIO}

Os diários de Breyner foram escritos entre 1 de janeiro de 1897 e 21 de outubro de 1933. Diário de um monárquico é um tipo de registro autobiográfico entrevisto por meio de uma agenda cotidiana familiar e profissional, cinzelada por reflexões do autor. Essas anotações breves formam domínios complementares e nitidamente definidos pela memorialística: o primeiro, de ordem objetiva, mais próximo da crônica histórica; o segundo, de cunho pessoal, propício à ensaística, muitas vezes em tom impressionista:

Na sua casa da correnteza das necessidades morreu hontem ao meio dia o Pedro d'Alcantara, velho particular da Rainha D. Maria Pia. Que bom e amável velho elle era! Foi a Turim buscar a Rainha quando ella veio para casar com El-Rei D. Luiz. Tinha 75 annos. Era muito meu amigo. (BREYNER; ANDRESEN, 1993, p. 21)

Clara Crabbé Rocha distinguiu a possibilidade de novas leituras dos diários do autor que, aparentemente, teria pensado na hipótese de seu futuro valor historiográfico:

D. Tomás de Mello Breyner concebe o diário como um gênero que tanto pode valer por si mesmo, como servir de matriz para outros gêneros autobiográficos eventualmente mais elaborados [...] Por isso junta o potencial interesse dos contemporâneos e vindouros pelo retrato de uma época ao interesse pessoal da rememoração intimista. Num brevíssimo balanço sobre as suas Memórias, e revelando que também cultiva um diário, cita os hábitos diarísticos dos ingleses e deplora os preconceitos dos portugueses do seu tempo a respeito do gênero: "Em Portugal, raras pessoas seguem este exemplo a que já tenho ouvido chamar caturreira. Pois com estas caturreiras se tem feito muita história verídica” (BREYNER apud ROCHA, 1992, 189)

Ao distinguir os textos memorialísticos, Jerome de Groot notou que a publicação de diários pode ser considerada uma tentativa de automemorização e, devido ao elemento premente, algo menos autocentrado que uma autobiografia. Em outra instância, a publicação de um diário ofere- 
ceria meios imediatos de esclarecer fatos do passado, notadamente se polêmicos, conferindo-lhes perspectiva histórica. Este senso da importância arquivística do diário, a noção de que o leitor tem em mãos um documento histórico para compreender um passado recente de modo mais direto do que se o lograsse por outras fontes, é vital à recepção desse tipo de texto (GROOT, 2016, p. 39).

Enquanto documento privado, os apontamentos de Breyner demonstram um sentido de humor por vezes revestido de indignação ou nostálgica melancolia, mas sempre preservando o estilo de gentil-homem, conforme anotou em Fevereiro de 1908:

Jantar de família com grande berraria e chorrilhos d'asneiras. Nos tempos que vão correndo de tão má política e tão ruins paixões só se pode viver só. Continua uma primavera precoce com calor que afflige e deprime. (BREYNER; ANDRESEN, 1993, p. 65)

O diário de Breyner associa lembranças íntimas à crônica da vida política em Portugal, expressando as transformações sociais que o médico presenciou na Europa e em seu país. Castelo Branco Chaves incluiu os escritos de Breyner no seguinte quadro:

Fora de intuitos políticos e polémicos imediatos têm aparecido a esmo, ainda no tempo de uma geração que não está extinta, memórias que alcançam o fim da monarquia e vão acompanhando outras a existência da República. Dois cortesãos de cepa fidalga, homens de apurada ilustração, deixaram memórias que seus descendentes publicaram. Possuem qualidades e valores próprios do género. Refiro-me às memórias do $6^{\circ}$ marquês do Lavradio e de Tomás de Mello Breyner. (CHAVES, 1978, p. 50)

O estilo de Breyner é acessível, límpido, depurado através de linguagem clara, direta e precisa: "Por ser meticuloso e 'um príncipe do espírito', como o designou Reynaldo dos Santos, os escritos de Thomaz de Mello Breyner são um testemunho fascinante do final da monarquia, I República e advento do Estado Novo" (RAMALHO, 2016). Para Castelo Branco Chaves $(1978$, p. 7), o caráter literário do gênero memorialístico nota-se por seu valor estético e habilidade de representação humana, fatores que dependem mais do talento e riqueza íntima do autor que da matéria narrada:

Sem obedecerem a regras da composição de conjuntos, nem harmonização de partes com o todo, os diários registram cotidianamente os factos, as impressões, as ideias ao sabor da sua fluência. O diário é uma obra de jornalismo íntimo, e por essa feição jornalística, se participa da efemeridade do cotidiano, por um lado, ganha por outro da genuinidade do imediato. Será um documento valioso, na maioria dos casos, mas só excepcionalmente constituirá obra de categoria literária, a não ser que seja um autêntico escritor a mantê-lo no propósito de deixar uma obra de tal feição e categoria. (CHAVES, 1978, p. 8) 
Hayden White (2002) discutiu a questão do caráter da narrativa histórica, considerada como artefato verbal, visando ser um modelo de estruturas e processos do passado e, portanto, fora do alcance do controle de qualquer observação experimental. Contingente e provisória, suscetível de infinitas revisões à luz de novas evidências ou mera conceituação de problemas, a recordação proposta pela narrativa histórica seria sempre incompleta, devido à natureza transitória da caracterização de eventos e agentes.

A estrutura da narrativa histórica nunca interessou a teóricos literários. Em geral, tem existido relutância em considerar narrativas históricas o que manifestadamente são: ficções verbais, cujos conteúdos podem ser tanto criados quanto existentes, com suas contrapartes mais identificadas à literatura que às ciências (WHITE, 2002, p. 192, ênfase do autor). O valor fixado à narratividade na representação de eventos reais fundamentar-se-ia no desejo de expor a coerência, integridade, plenitude e proximidade de uma imagem da vida que é e somente pode ser imaginária (WHITE, 1996, p. 284).

Nesse sentido, White ratificaria o pensamento do analista da Historiografia, J. G. A. Pocock, segundo o qual teorias históricas e políticas provêm de ideias que as sociedades fazem de si mesmas. Essas ideias seriam intrínsecas ao conceito de sociedade: cada grupo social depende de autoimagens, modos de agir e viver a que denominam tradição (POCOCK, 1971 apud MCGRATTAN, p. 106). Assim, narrativas históricas derivariam de ideias sobre comunidades (MCGRATTAN, p. 109). Uma das funções dos textos memorialísticos seria legar imagens pessoais dessas ideias ao futuro.

\section{UM MÉDICO “AO PÉ D’EL-REI”}

Encontrar o retrato fidedigno do autor e da época de um diário - sem comprometer sua autenticidade - é um desafio para biógrafos, editores e leitores, desde que o material publicado tenha sofrido revisões seletivas, eliminando repetições ou trechos não autorizados. Castelo Branco Chaves contextualizou com palavras do $6^{\circ}$ marquês do Lavradio o período em que se inscrevem as memórias e diários de Breyner:

Na leitura das suas páginas se vislumbra que de 1875 a 1908 houve em Portugal, para as classes aristocráticas, uma época de "douceur de vivre" que, em todas as sociedades e em todos os tempos, prenunciam e precedem a sua extinção. "Quem viveu os últimos vinte e seis anos do século passado e os primeiros deste - escreveu o marquês do Lavradio não esqueceu certamente quanto era fácil, despreocupada e alegre a vida de Lisboa. A alta sociedade desse tempo era 'civilizada' e escolhida, existindo ainda a chamada 'vida de sociedade', que a geração de hoje ignora”. É do ponto de vista desta "alta sociedade" que tanto este como Tomás de Mello Breyner viam as transformações que se iam operando na vida social portuguesa. (CHAVES, 1978, p. 50)

A experiência individual faz do diário um gênero híbrido, pois embora a documentação da realidade seja de ordem subjetiva, nem todo 
fato citado pertence à esfera pessoal - memórias, impressões alheias e coletivas também seriam registradas: "Morreu esta manhã na sua casa do arco d'Arroyos meu amigo Luiz d'Araujo e popular poeta dum grande chiste. Eu achava-lhe muita graça e já meu pae o admirava. Morreu com 75 annos. Foi um pandigo honrado" (BREYNER; ANDRESEN, 1993, p. 20). Essa variedade de informações do diário é um dos indicativos da complexidade do gênero:

Escritos ao correr da pena, estes diários mostram a atenção de Thomaz de Mello Breyner a tudo o que o rodeava, mesmo os pormenores mais simples, como o estado do tempo. Pela forma como foram escritos, pela quantidade e variedade de informação, pelo meio social e profissional em que Mello Breyner se movimentou e, sobretudo, por constituírem um registro diário de 36 anos, são um dos testemunhos históricos mais importantes da vida portuguesa entre 1897 e 1933. (RAMALHO, 2016)

Quem protagoniza Diário de um monárquico não é o jovem médico treinado no exterior, empenhado na aquisição de inovações técnicas e a par dos últimos avanços médicos, e sim o que lida diariamente com uma população exposta a moléstias ainda letais na Europa do século XIX: cólera, coqueluche, crupe, disenteria, escarlatina, sífilis, tifo e tuberculose. Apesar do avanço técnico-científico da Revolução industrial, cabia à medicina nos países em desenvolvimento obter novas soluções para velhos problemas: "Este excelente e talentoso Alberto Paiva de Moraes, Capitão d'Estado Maior, morreu ante-hontem no Porto victimado por um cancro na língua. Imaginando ter syphilis consultou-me em tempos" (BREYNER, ANDRESEN, 1993, p. 325).

No século XIX, havia nítida distinção entre os termos médico, cirurgião e boticário - em escala ascendente, o primeiro ocuparia a base e o último, o topo da pirâmide social. Mais prestigiado, não raro o médico era recebido como hóspede ilustre em visita à casa do doente, por vezes tornando-se extensão do grupo familiar. Essas antigas categorias, conforme Alison Adam (2016, p. 22), bem antes da metade do século XIX, em termos de prática, diluíam-se na divisão entre a nova elite de consultores dos hospitais e a classe dos clínicos gerais. Contudo, a velha distinção perduraria segundo estivessem institucionalizadas nas corporações representativas de suas funções médicas, a exemplo do renomado Colégio Real de Médicos de Londres, Dublin e Edimburgo.

A ascensão social da categoria médica não se restringiu à aspiração ao estatuto de cavalheiro entre a elite profissional e à exclusão dos desqualificados, mas evidenciou a noção de quão científico seria o conhecimento e o quanto aquilataria uma reputação.

O saber científico tornara-se a base para o estudo do mundo natural e o médico preocupava-se em orientar e consolidar sua atuação por este parâmetro (ADAM, 2016, p. 22-3). Nesses moldes, conforme observou 
Sara Repolho, Sousa Martins tem "uma carreira ascendente e brilhante, como professor da Escola Médica, como clínico, particular e no Hospital São José, como membro de inúmeras comissões e sociedades" (REPOLHO, 2008, p. 16). Breyner seguiria os passos de Sousa Martins, tornando-se professor de Dermatologia e Venerologia da Escola Médica e sócio da Academia das Ciências de Lisboa: "De manhã Hospital. Fiz grande prelação diante de muitos estudantes e injetei duas doentes da enfermaria da Piedade com o novo remédio 606 contra a syphilis, descoberta do Professor Ehrlich" (BREYNER; ANDRESEN, 1993, p. 320). O diário do Conde de Mafra registra, igualmente, uma vida social ativa ao lado da família - confraternizações, passeios, viagens e eventos culturais são citados com frequencia:

Das 2 ás 4 h. consultório. De tarde foi a Sophia buscar-me para dar uma volta. Hoje é a primeira da famosa peça de Rostand "Le Chantecler". Como dizem ser uma pepineira principalmente com esta companhia de $6^{\mathrm{a}}$ ordem não vou. Tempo quente. (BREYNER; ANDRESEN, 1993, p. 259)

Outra face culturalmente rica da prosa memorialística de Breyner refere-se à política. Autobiografias, diários, memórias e testemunhos constituem meios adicionais à História narrativa para se vislumbrar vidas e eventos do passado. O diário político, similar à epistolografia, concederia acesso irrestrito a certas matérias e personalidades. Documento original, editado ou não com suas idiossincrasias, aproximaria o leitor da investigação histórica de modo diverso da Historiografia tradicional (GROOT, 2016).

Relato individual ratificado pela personalidade e reputação do autor, o diário político torna-se ato de esclarecimento, justificação ou retratação pública, produzindo um legado instantâneo, de considerável valor para os envolvidos. Ser história "em estado bruto" é parte de seu apelo. No entanto, imperfeitos em seu modo particular de reordenar o passado, podem converter-se em investimento ideológico oportuno (GROOT, 2016, p. 39). "São as épocas de convulsão social ou meramente política aquelas que suscitam a literatura memorialística", notou Castelo Branco Chaves (1978, p. 8), sobre o aspecto que o diário político assumiria quando redigido tendenciosamente:

[...] escrito num intuito de vingança e publicado no propósito de auferir rendimentos pecuniosos do escândalo, deturpa factos, calunia amigos, deixando apenas revelar a má natureza moral do seu autor que, cônscio da sua frustração, pretende sobressair pelo rebaixamento dos outros. (CHAVES, 1978, p. 48-49)

Se redigido, o testemunho é capaz de criar uma interface com a História. $\mathrm{O}$ enfoque dado às palavras e experiência do depoente possui irresistível apelo emocional, principalmente quando se refere a acontecimentos dramáticos. A tirania do testemunho consiste no peso atribuído às suas palavras, explicou Groot (2010, p. 40), a despeito das intenções do autor. Projetos memorialísticos coletivos diferem de um projeto individual, 
segundo o autor: coletâneas de testemunhos, pela multiplicidade de vozes, atraem novas interpretações, inclusive propositalmente orientadas à determinada interpretação de um evento-chave. O testemunho de familiares e pessoas próximas é outro poderoso efeito de sentido na exposição de fatos ou perfis biográficos. Observe-se no trecho seguinte o retrato que Breyner expõe de Christian Friedrich Ludwig, Conde von Tattenbach (1846-1910), que atuou como ministro alemão, em Lisboa, de 1897 a 1908:

Quando íamos para o jantar disse-me El-Rei que tinha recebido um telegrama de Madrid anunciando a morte do Conde de Tattenbach embaixador d'Allemanha n'aquella Côrte e durante muito tempo ministro aqui. Era um homem brusco, mas inteligente e bom. Não me esquecerei que ele com a mulher correram a este Paço em 1 de Fevereiro de 1908 á noite quando não havia cá muita gente. Vi-o pela primeira vez em Madrid (...) Era catholico. (BREYNER; ANDRESEN, 1993, p. 242)

Singularmente, na sexta-feira de 31 de janeiro de 1908, dia anterior ao atentado que matou o Rei Dom Carlos e o Príncipe Luís Filipe, Breyner fez a seguinte anotação:

Receiam-se distúrbios e eu quero estar ao pé d’El Rei. Há grande excitação em toda a gente. Valha-nos Deus. Tempo bonito, o vento abrandou. Vai mal o tempo para a política. Fui avisado pelo meu empregado Roberto, do Hospital, de que uma grande desgraça se prepara. Querem matar o meu querido Rei, tão bom para todos. Que horror! (BREYNER; ANDRESEN, 1993, p. 26)

Tempos depois, na quinta-feira de 26 de março de 1908, elogiaria "Rei Dom Carlos, o Martirizado", defesa póstuma e necrológio reproduzido na imprensa da época:

“Tempo ventoso e nublado. O jornal Portugal publica hoje um brilhante artigo do grande Ramalho Ortigão sobre El-Rei D. Carlos. Bem haja o illustre escritor que tem o desassombro de pôr o que é justo em lettra redonda. Bravo seu Ramalho" (BREYNER; ANDRESEN, 1993, p. 47). No diário, "pôr o que é justo em lettra redonda" compreende dois aspectos essenciais do gênero memorialístico: sua função e recepção.

De acordo com Irina Paperno (2004, p. 532), todo diário teria por base uma voz em primeira pessoa, cuja função seria relatar experiências e impressões do autor, situando-as no espaço e no tempo. A recepção implicaria a possibilidade de esses escritos serem acessíveis a futuros leitores. Se o autor considerar tal hipótese em vida, caso de Breyner, o diário como arquivo familiar pode tornar-se patrimônio de interesse público.

Nesse sentido, a família pode determinar a recepção do diário, segundo revela o comentário de Eduardo Macieira Coelho (2004, p. 32), "[...] genro de uma das filhas de D. Thomaz, Conde de Mafra, Dona Maria da Conceição Mello Breyner Cabral”: 
Surpreendeu-me observar um longo período do "Diário" propositalmente ilegível, porque o texto estava apagado por uma tinta azul espessa que impossibilitava a leitura. Perguntei a minha sogra o que provocara a deliberada inutilização do texto. Minha sogra disse-me então que sua mãe, a Condessa de Mafra, depois da morte de D. Thomaz, entendeu que o que estava escrito poderia ser mal aproveitado por eventuais historiadores que não relatam a História mas que refazem a História. Mello Breyner fora médico do Paço e amigo do Rei D. Carlos. Nesse texto havia referências a situações que condicionaram o rumo de certos acontecimentos. (COELHO, 2004, p. 32)

O diário de Breyner revela crescente desencanto com a política: "Vae grande reboliço nas Câmaras. Não sei como agradecer á sorte ver-me fora daquelle odioso meio. A política é realmente uma marafona, como dizia o Sousa Martins" (BREYNER; ANDRESEN, 1993, p. 65). O tom confessional surge na descrição de algumas cenas:

Vejo com profundo desgosto que E-Rei D. Manuel II diz muitas grossarias ao seu serviço, principalmente ás pessoas com quem joga. Nem o Tio Affonso, tão bom e dedicado, escapa á fúria do jovem Monarcha. Deus queira que nunca seja comigo. (BREYNER; ANDRESEN, 1993, p. 75)

O estilo contido do autor não encobre o apreço e lealdade à família real: "Chegamos em automóveis tendo partido do Paço das Necessidades ás 10 1/2. Mau caminho [...] Que impressão e que saudades do querido Rei e do querido Príncipe! A maior homenagem que pode prestar-se aos que morreram é dedicar-se aos que ficaram" (BREYNER; ANDRESEN, 1993, p. 240). No diário de Breyner, a experiência pessoal registrada na forma de jornal íntimo também pode rememorar o passado através de uma narrativa ou comentário: "Está tudo em grandes preparativos para as festas de Nazareth. Lembro-me de andar há 34 annos com a mesma azafama com que andam os meus pequenos na preparação das luminárias" (BREYNER; ANDRESEN, 1993, p. 185).

Para historiadores acadêmicos ou não acadêmicos, diários como os de Breyner são particularmente interessantes, representando complexo sistema arquivístico de caráter pessoal, o que problematiza sua recepção ou audiência. Se esses escritos possuem forte apelo popular por sua inclinação à historicidade, conforme aferiu Groot (2016), convém observar suas limitações quando se pretende elucidar fatos do passado. Nesse sentido, Andresen advertiu o leitor: "Depois da morte de meu Avô, entendeu minha Avó materna, Sophia Burnay de Mello Breyner - Condessa de Mafra, riscar e apagar linhas e até páginas inteiras do diário" (BREYNER; ANDRESEN, 1993, p. 6).

Aliado ao discurso confessional, os principais traços do diário ou jornal íntimo seriam a confiabilidade e autenticidade. Devido à natureza supostamente não ficcional do diário, o leitor tende a julgar as revelações 
do autor verossímeis e isentas de artifícios literários. Logo, quanto mais literário o texto, mais claramente se denota seu caráter ficcional através de marcas como ironia, paródia, autorreflexão, uso de linguagem poética ou simbólica e estruturas narrativas complexas - e menos o leitor reconhece o texto como expressão autorial autêntica. Consequentemente, fatores estéticos seriam secundários para os leitores desse gênero, explicou Joanne Tidwell (2008, p. 38).

\section{CONSIDERAÇÕES FINAIS}

Avaliadas pelo valor histórico do testemunho, as notas habituais de Breyner formam uma galeria de cenas que, devido à escrita por vezes quase telegráfica, afastar-se-ia da prosa diarística marcada por digressões esteticamente elaboradas. Mas, em breves narrativas, cada fato significativo é "capturado" com precisão fotográfica, seguido de reflexões que, mesmo sem outorgar estatuto de obra literária a seu diário, distanciam-no do caráter historicizante estrito ao interpretar com emoção e humor o trabalho - falível - da consciência, da memória e do julgamento subjetivo.

O crítico literário e o historiador das mentalidades têm propósitos e recursos específicos no enfoque da memorialística. A contribuição entre as áreas ampliaria o estudo do diário como artefato material, artístico, patrimônio arquivístico e produto cultural, considerando a abrangência do tema e exemplares publicados no último século.

\section{REFERÊNCIAS BIBLIOGRÁFICAS}

ADAM, Alison. A History of Forensic Science: British Beginnings in the Twentieth Century. New York: Routledge, 2016.

ANDRADE, Ferreira de. As Antigas Portas de São Lourenço, da Alfofa e de S.to André. Olisipo. Lisboa, ano XIII, n. 89, p. 11-36, jan. 1960.

BERNARDO, Luís Miguel. História da Luz e das Cores. 2a ed. Porto: Editora da Universidade do Porto, 2009.

BREYNER, José Tomaz Mello. Regicídio "In Memoriam”. 2008. Disponível em: http://regicidiomemoria.blogspot.com.br/. Acesso em: 13/05/2017.

BREYNER, Thomaz de Mello; ANDRESEN, Gustavo de Mello Breyner. Diário de um monárquico (1908-1910). Porto: Editora Rocha, 1993.

CANDIDO, Antonio. Poesia e ficção na autobiografia. In: A educação pela noite e outros ensaios. São Paulo: Ática, 1989, p. 51-69.

CHAVES, Castelo Branco. Memorialistas portugueses. Amadora: Livraria Bertrand, 1978.

CLODE, João José P. Edward. História da fotografia e da sua aplicação à medicina. Cadernos Otorrinolaringologia. Lisboa, v. 2, nº 1, p. 1-24, dez. 
2010. Disponível em: http://www.cadernosorl.com/artigos/13/2.pdf. Acesso em: 13/05/2017.

COELHO, Eduardo Macieira. D. Thomaz de Mello Breyner: médico, aristocrata e homem de humor. Revista Ordem dos Médicos. Lisboa, v. 20, no 48, p. 32-35, julho/ago. 2004. Disponível em: https://www.ordemdosmedicos.pt/.../ficheiros-bin2_ficheiro_pt_0681355001202133928.... Acesso em: $02 / 08 / 2017$.

GRAÇA, Luís. A vida de um médico português na Belle Époque. 2005. Disponível em: http://www.ensp.unl.pt/luis.graca/textos178.html. Acesso em: 13/05/2017.

GROOT, Jerome de. Consuming History: Historians and Heritage in Contemporary Popular Culture. 2nd ed. London and New York: Routledge, 2016.

FERREIRA, Francisco António Gonçalves. História da saúde e dos serviços de saúde em Portugal. Lisboa: Fundação Calouste Gulbenkian, 1990.

FIELD, Trevor. Form and Function in the Diary Novel. New Jersey: Barnes \& Nobles Book, 1989.

LEO TOLSTOY'S AUTOBIOGRAPHICAL WRITINGS RELEASED ON THE WEB. Russkiy Mir Foundation, 09 set. 2014. Disponível em: https://russkiymir.ru/en/news/149813/. Acesso em: 13/05/2017.

LOPES, Maria Antónia. Maria Pia de Sabóia (1847-1911), Rainha de Portugal: um pilar da monarquia portuguesa e das relações Portugal-Itália. In: LOPES, Maria Antónia; BLYTE, Alice Raviola. Portugal e o Piemonte: a casa real portuguesa e os sabóias: nove séculos de relações dinásticas e destinos políticos (XII-XX). Coimbra: Imprensa da Universidade, 2013, p. 239-300.

MCGRatTan, Cillian. Memory, Politics and Identity: Haunted by History. New York: Palgrave Macmillan, 2013.

MISHRA, Shivashankar. Rise of William Blake. New Delhi: Mittal Publications, 1990.

RAMALHO, Margarida de Magalhães. Thomaz de Mello Breyner e a Grande Guerra, A Guerra de 1914 - 1918. Portugal 1914 - 1918, Centenário da I Guerra Mundial. Lisboa: Faculdade de Ciências Sociais e Humanas, 24 de jul. 2014. Disponível em: http://www.portugal1914.org/portal/ pt/historia/a-guerra-1914-1918/item/7197-thomaz-de-mello-breyner-e-a-grande-guerra. Acesso em: 13/05/2017.

. Um cronista invulgar. Expresso, Lisboa, 3 de set. 2016. Disponível em: http://expresso.sapo.pt/sociedade/2016-09-11-Um-cronista-invulgar. Acesso em: 13/05/2017.

REPOLHO, Sara. Sousa Martins: ciência e espiritualismo. Coimbra: Imprensa da Universidade de Coimbra, 2008. 
ROCHA, Clara Crabbé. Máscaras de Narciso: estudos sobre a literatura autobiográfica em Portugal. Coimbra: Almedina, 1992.

SCHWARZ, Daniel R. Reading the Modern British and Irish Novel 1890 - 1930. Malden: Blackwell Publishing, 2003.

TIDWELL, Joane. Politics and Aesthetics in the Diary of Virginia Woolf. New York: Routledge, 2008.

WAKABWE, Desiré. Ecritures aux dimensions autobiographiques: les cas de V.Y. Mudimbe et P. Ngandu Nkashama. French Studies in Southern Africa, n. 34, p. 122-137, jan. 2005.

WHITE, Hayden. The Historical Text as Literary Artifact. In: RICHARDISON, Brian (Ed.). Narrative Dynamics: Essays on Time, Plot, Closure, and Frames. Columbus: The Ohio State University Press, 2002, p. 191-210.

. The Value of Narrativity in the Representation of Reality. In: ONEGA, Susana; LANDA, José Angel García. Narratology: An Introduction. London: Longman, 1996, p. 273-285.

Recebido para publicação em 31/05/2017

Aprovado em 15/09/2017

\section{NOTAS}

1 Doutora em História Social pela Universidade de São Paulo (USP). Pesquisadora vinculada ao grupo Variações do Insólito: do mito clássico à modernidade. UFPB/CNPq. 